\title{
A comparison of light backscattering and particle size distribution measurements in tropical cirrus clouds
}

\author{
F. Cairo ${ }^{1}$, G. Di Donfrancesco ${ }^{2}$, M. Snels ${ }^{1}$, F. Fierli ${ }^{1}$, M. Viterbini ${ }^{1}$, S. Borrmann ${ }^{3,4}$, and W. Frey ${ }^{3}$ \\ ${ }^{1}$ Istituto di Scienze dell'Atmosfera e del Clima, Consiglio Nazionale delle Ricerche, Roma, Italy \\ ${ }^{2}$ Ente Nazionale per le Nuove tecnologie, l'Energia e l'Ambiente, Frascati, Italy \\ ${ }^{3}$ Institute of Atmospheric Physics, University of Mainz, Mainz, Germany \\ ${ }^{4}$ Max-Planck Institute for Chemistry, Particle Chemistry Department, Mainz, Germany
}

Received: 6 May 2010 - Published in Atmos. Meas. Tech. Discuss.: 9 September 2010

Revised: 22 December 2010 - Accepted: 1 March 2011 - Published: 17 March 2011

\begin{abstract}
An FSSP-100 Optical Particle Counter designed to count and size particles in the micron range and a backscattersonde that measures in-situ particle optical properties such as backscatter and depolarization ratio, are part of the payload of the high altitude research aircraft M55 Geophysica. This aircraft was deployed in tropical field campaigns in Bauru, Brasil (TROCCINOX, 2004) Darwin, Australia (SCOUT-Darwin, 2005) and Ouagadougou, Burkina Faso (SCOUT-AMMA, 2006). In those occasions, measurements of particle size distributions and optical properties within cirrus cloud were performed. Scope of the present work is to assess and discuss the consistency between the particle volume backscatter coefficient observed by the backscattersonde and the same parameter retrieved by optical scattering theory applied to particle size distributions as measured by the FSSP-100. In addition, empirical relationships linking the optical properties measured in-situ by the backscattersonde, which generally can be obtained by remote sensing techniques (LIDAR), and microphysical bulk properties like total particle number, surface and volume density will be presented and discussed.
\end{abstract}

\section{Introduction}

Cirrus clouds are a fundamental component of the climate system (Liou, 1986), due to their pivotal role in the water balance and in the radiative properties of the atmosphere,

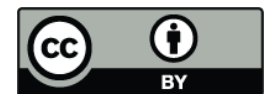

Correspondence to: F. Cairo

(f.cairo@isac.cnr.it) impacting both its thermal structure and dynamics. Satellite observations have provided a global picture of their distribution, that basically follows cloud activity, i.e. deep convection in the tropics and frontal zones in midlatitudes. In the tropics their occurrence tends to concentrate near the tropopause level, with a thickness from a few tens of meters to few kilometers, horizontal homogeneity extending to thousands of kilometers and lifetimes that can reach days. Tropical cirrus clouds have raised a particular interest for the role they play in the chemical processing and dehydration of air entering the tropical lower stratosphere and for their contribution to the radiative balance of the Tropical Tropopause Layer (Hartmann et al., 2001; Holton and Gettelman, 2001; Luo et al., 2003; Corti et al., 2006). Because of their often small optical depths, ground based lidars are suitable instruments for cirrus characterization. High tropical cirrus were first reported by Uthe and Russell (1976) who observed cirrus clouds between 12 and $18 \mathrm{~km}$, from the ground lidar station at Kwajalein $\left(8.7^{\circ} \mathrm{N}, 167.7^{\circ} \mathrm{E}\right)$. Since then, a molteplicity of lidar studies characterized cirrus morphology, often in conjunction with other remote sensing instruments as infrared radiometers or millimeter radars (Platt et al., 1998; Comstock and Sassen, 2001; Wang et al., 2001; Pace et al., 2003; Immler et al., 2007).

In parallel, aircraft campaigns have been conducted to provide their in-situ characterization. In-situ measurements in the upper tropical troposphere have been discussed by Heymsfield (1986), who reported ice crystals with sizes up to $50 \mu \mathrm{m}$ and Knollenberg et al. (1993) who observed high concentrations of ice crystals $\left(\geq 10 \mathrm{~cm}^{-3}\right)$ in the anvils of tropical convective systems. McFarquhar et al. (2004) have reported maximum ice crystal sizes of between 30 and $140 \mu \mathrm{m}$

Published by Copernicus Publications on behalf of the European Geosciences Union. 
and modal radius of few tens of $\mu \mathrm{m}$ on a similar thin subvisible cirrus layer over the tropical central Pacific. Size distributions of cirrus clouds in the upper tropical troposphere, exhibiting size diameters with pronounced peak at $10 \mu \mathrm{m}$, have been reported by Thomas et al. (2002), presenting observations taken on board the high altitude research aircraft M55 Geophysica. Ultrathin tropical tropospheric clouds (UTTC) were observed directly beneath the tropical tropopause, characterised by a very low ice crystal number concentration $\left(0.05 \mathrm{~cm}^{-3}\right)$, and a size diameters modal peak of 10 to $12 \mu \mathrm{m}$ (Peter et al., 2003).

De Reus et al. (2009) reported cirrus measurements showing a peak in the ice crystal number size distribution at about $10 \mu \mathrm{m}$ diameter, while Lawson et al. (2008) reported subvisible cirrus observations from Costa Rica with average values of ice particle number concentration $\left(0.066 \mathrm{~cm}^{-3}\right)$, and effective radius $(8.82 \mu \mathrm{m})$ similar to those by McFarquhar et al. (2004).

The observations performed from the M55 Geophysica, hosting a backscattersonde and an instrumental set for particle counting and sizing, represent a unique dataset linking in-situ observations of both microphysical properties and optical parameters of cirrus clouds usually obtained by remote sensing lidars. One of the geophysical observables of the elastic lidar technique is the particle volume backscattering coefficient. The backscattersonde offers an advantage with respect to the lidar, whose measurement of backscattering is affected by the molecular and particle extinction along the laser optical path. In fact, the molecular extinction can be evaluated by the Rayleigh scattering theory from measurement of air density, or from a suitable atmospheric model, while the particle contribution to backscattering and extinction coefficients is unknown. Both quantities are present in the lidar equation and have to be retrieved from measurements. Different inversion techniques have been reported in the literature to properly account for that effect (Klett , 1981; Fernald, 1984; Young, 1995), all assuming some a priori relationship between particle backscattering and extinction. Such assumption is itself a source of uncertainty for the lidar derived particle backscatter coefficient (Russell et al., 1979). Attenuation is, on the contrary, of no concern in backscattersonde measurements: the instrument performs optically unattenuated in-situ measurements. Obviously, once the effect of attenuation has properly been taken into account in the lidar inversion, the lidar retrieved backscattering coefficient should attain - within its limits of accuracy and precision that same value possibly measured in situ by a backscattersonde.

The possibility of connecting quantities that could be remotely observed with in-situ cirrus characterization has driven this work, whose aim is to assess and discuss the consistency between the particle volume backscatter coefficient $\beta$ observed by the backscattersonde and the same parameter computed by optical scattering theory applied to the size distributions measured by the optical particle counter and sizer.
Empirical relationships between $\beta$ and the bulk microphysical parameters of the size distribution, such as total number of particles, surface and volume densities, will be presented and discussed.

\section{Instrumentation and methods}

\subsection{Instruments and measurements}

The M55 Geophysica is equipped with a complete set of instrumentation for the in-situ chemical and microphysical characterisation of the sampled airmass, including condensation nuclei counters, optical counters and sizers, particle imagers, hygrometers and chemical analyzers.

An optical particle counter FSSP-SPP-100 is located in a boom beneath the left wing of the aircraft, facing forward, while the backscattersonde is in a bay beneath the pilot's cockpit, facing sideways on the right. The separation between the airmasses sampled by the two instruments is only a few metres and the two instruments can thus be considered to perform simultaneous co-located in situ observations.

The backscattersonde MAS (Multiwavelength Aerosol Scatterometer) (Buontempo et al., 2006; Cairo et al., 2004) emits polarized laser light at $532 \mathrm{~nm}$ and at $1064 \mathrm{~nm}$ and collects the light backscattered from the portion of atmosphere in close proximity (3-10 m) to the instrument, so it acts as a detector of optically detectable (i.e. whose diameter is greater than few tenths of $\mu \mathrm{m}$ ) cloud particles and aerosols. Polarization resolved light backscattering observations allow to discriminate particle shape, hence thermodynamical phase. The instrument is basically an elastic lidar system that measures in-situ, i.e. at few metres from the mounting platform, the same atmospheric parameters which are accessible to remote sensing ground based lidar investigations, i.e. depolarization ratio $\delta$, backscatter ratio $R$ and color index $C$ (Matthias et al., 2004; Böckmann et al., 2004; Pappalardo et al., 2004).

The sampling volume is approximatively $10^{-3} \mathrm{~m}^{-3}$, the resolution is $5 \mathrm{~s}$, corresponding to $1 \mathrm{~km}$ horizontal resolution along the aircraft trajectory, given the average $200 \mathrm{~m} \mathrm{~s}^{-1}$ aircraft speed. The backscatter ratio $R=\left(\beta+\beta_{m}\right) / \beta_{m}$ where $\beta_{m}$ is the molecular backscattering coefficient, is retrieved from the backscattered light signal $P$ by a calibration procedure that uses the pressure $p$ and temperature $T$ in the state equation of the ideal gas to retrieve the air density, and defines a suitable constant $K$ - taking into account the molecular scattering cross section as well as the instrumental sensitivity - in order to ensure that $R=K \cdot P \cdot(p / T)$ equals 1 in airmasses where no particles are present. A total Backscatter Ratio has been computed by summing its parallel and cross components, with respect to the polarization of the emitted laser light.

The particle volume backscattering coefficient is defined as $\beta=\int_{0}^{\infty} n(r) \cdot d r \sigma_{\pi}(r) \cdot n n d r$, where $\sigma_{\pi}(r)$ is the particle backscattering cross section and $n(r)$ is the particle size 
distribution, defined as the number of particles, in a given volume, whose radius is within the limits $r$ and $r+d r$. This quantity can be retrieved from the experimentally determined $R$ by the following expression (Collis and Russell, 1976):

$\beta=(R-1) \cdot\left(\frac{p}{T}\right) \cdot C_{\lambda} \times 10^{-9} \mathrm{~m}^{-1} \mathrm{sr}^{-1}$

where $C_{532 \mathrm{~nm}}=4.508$ and $C_{1064 \mathrm{~nm}}=0.280$ when $p$ is expressed in $P a$ and $T$ in $K$. In our case, $p$ and $T$ are provided by the M55 avionic data system. Taking into account the uncertainties in $P, p, T$ and in the calibration procedure, the backscattering coefficient at $532 \mathrm{~nm}$, the one we have used in our study, has a precision of $10 \%$ and an accuracy of $5 \times 10^{-9} \mathrm{~m}^{-1} \mathrm{sr}^{-1}$, in the worse case when observations are taken at $21 \mathrm{~km}$ of altitude, which is the Geophysica ceiling level.

The optical particle counter FSSP-SPP-100 detects and sizes particles by measuring the forward scattered laser light of single particles within a scattering angle of $4^{\circ}-12^{\circ}$ within a sampling volume of approximately $10^{-6} \mathrm{~m}^{3}$, detecting particles whose diameters are roughly between $2.7 \mu \mathrm{m}$ and $31 \mu \mathrm{m}$. The time resolution of the FSSP can be made as small as $2 \mathrm{~s}$, if sufficient counting statistics is available, i.e. in thick clouds.

Using optical scattering theory, the size of a particle is related to the measured scattering cross section. The particle size distribution $n(r)$ is approximated by a histogram $n_{i}=n\left(r ; \Delta r_{i}\right)$ defined as the numbers of particles whose radius is within a set of size bins $\Delta r_{i}=\left(r_{i}, r_{i}+\Delta_{i}\right)$. In principle the histogram may consist of up to 40 unequal size bins, but this resolution is usually reduced to below 10 bins ( 7 in the present study) to overcome ambiguities linked to the relationship between light scattering intensity and particle size, which is not always univocal, and to increase the counting statistics in the single bin. The uncertainties of the number concentrations reported by the FSSP are determined by the uncertainty of the sample volume (approximately 20\%) and mostly by poor counting statistics at low number densities like those encountered in thin or subvisual cirrus clouds (Thomas et al., 2002). To increase counting statistics, data are averaged over $10 \mathrm{~s}$ in cirrus clouds, or to several minutes in clear air. From the histogram, the total particle number $N$, surface $S$ and volume density $V$ can be retrieved, as well as a particle effective radius $r_{\text {eff }}=V / S$.

The FSSP instrument has been extensively used in airborne cloud research since many decades (Dye and Baumgardner, 1984). The version on board the Geophysica has been modified by implementing digital signal processor electronics (DMT Inc, Boulder, Colorado, USA) and specific changes necessary for the ambiental conditions encountered in the upper troposphere and lower stratosphere.

Both instruments have been deployed in tropical campaigns: during February 2006 in Bauru, Brasil, in the framework of the EU funded project TROCCINOX (Schumann, 2005), during November 2005 in Darwin, Australia, in the framework of the EU funded project SCOUT-O3 (Brunner et al., 2009) and during August 2006 in Ouagadougou, Burkina Faso, in the framework of the EU funded projects SCOUTO3 and AMMA joint activities (Cairo et al., 2010).

Ten M55 Geophysica flights were chosen for the present analysis, when simultaneous measurements of optical parameters and size spectra were acquired in significant portions of flight time spent within cirrus clouds. These were identified as regions above $10000 \mathrm{~m}$, where appreciable backscattering $(\geq 1.02)$ and depolarization $(\geq 10 \%)$ were observed. Roughly $7000 \mathrm{~s}$ of observations came from the TROCCINOX campaign, $5000 \mathrm{~s}$ from the SCOUT-AMMA dataset, while $21000 \mathrm{~s}$ were from the SCOUT-Darwin campaign. The time series of the two instruments were interpolated to a common $10 \mathrm{~s}$ resolution time grid, corresponding to a spatial average over $2 \mathrm{~km}$ along the aircraft trajectory.

There may be concern on the dishomogeneity of such observations, since the SCOUT-Darwin campaign measurement strategy was focussed on measurement into fresh outflows from cumulonimbus anvils, while data from TROCCINOX and SCOUT-AMMA equally sampled fresh and aged outflows, as well as cirrus of different origins. Figure 1 shows the dispersion of our dataset in altitude ranges and different deployments. There, each of the eight panels (from a to $\mathrm{h}$ ) is related to a $1000 \mathrm{~m}$ altitude range from $10000 \mathrm{~m}$ to the ceiling altitude of the M55 Geophysica. In each panel, histograms of particle backscatter (left) as measured by MAS, and corresponding temperature (right) observations are shown, for the TROCCINOX (upper rows), SCOUTDarwin (middle rows) and SCOUT-AMMA (lower rows). By inspecting the histograms, we can see how the majority of observations comes from mid to high cirrus clouds, with small variability among the different deployments, due to the fact that cirrus sampled during SCOUT-AMMA were on the average lower, warmer and denser than those sampled during SCOUT Darwin, while TROCCINOX clouds have intermediate characteristics. The observed backscattering values ranges from subvisible to nearly opaque cirrus clouds. These results are summarized in Table 1 that shows the mean values and standard deviations of the particle densities within each bin of the FSSP size distribution histograms, as well as the mean and standard deviation of cloud altitudes and temperatures, for each of the three deployments.

\subsection{Optical modelling}

Particle backscattering coefficients were computed from the size distributions by means of light scattering theory as

$\beta=\int_{0}^{\infty} n(r) \cdot \pi \cdot r^{2} \cdot Q(r) \cdot d r$

where the backscattering cross section $\sigma_{\pi}(r)$ is expressed in terms of a geometrical cross section $\pi \cdot r^{2}$ and a scattering efficiency $Q(r)$. This latter quantity, depending on wavelength and particle refractive index, was computed by mean 


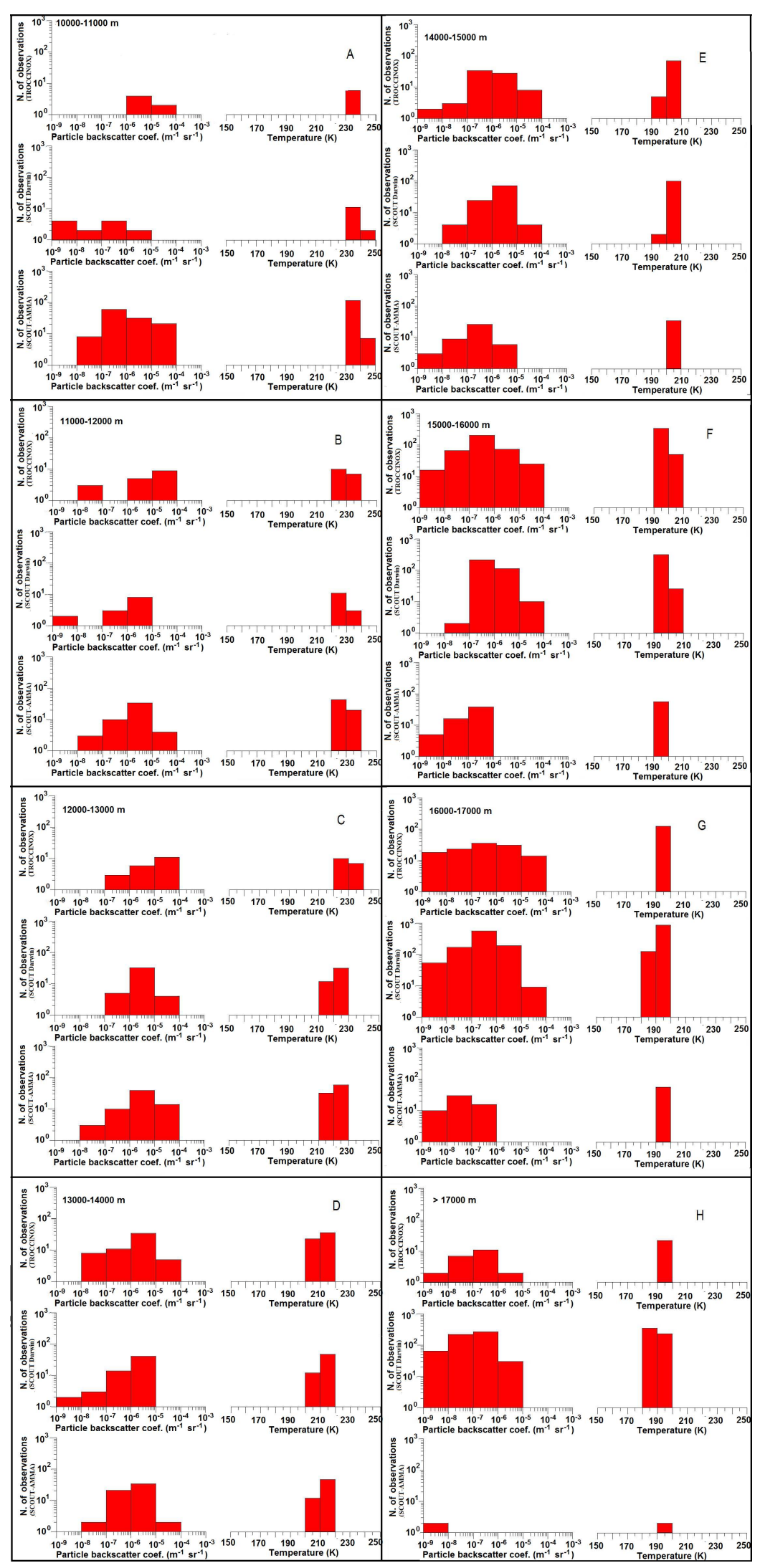

Fig. 1. Panels (A) through $(\mathbf{H})$ show, for altitude ranges from $10000 \mathrm{~m}$ to $17000 \mathrm{~m}$ in $1000 \mathrm{~m}$ steps, the histograms of the measured backscatter coefficients, (left) and temperatures (right). In each panel, the observations have been grouped into different campaigns: SCOUTAMMA, SCOUT Darwin and TROCCINOX respectively, from bottom to top. 
Table 1. Averages and standard deviations of the particle density in $\mathrm{cm}^{-3}$ within each diameter bin of the size distribution histogram are reported, as measured by the FSSP-100, for clouds observed in each of the three M55 Geophysica deployments (TROCCINOX, Bauru, 2004; SCOUT-Darwin; Darwin, 2005; SCOUT-AMMA; Ouagadougou, 2006). The diameter range of each bin is reported in the second row of the table, where minimum and maximum particle diameter for each bin are reported. In the two columns on the right, the mean value and standard deviation of cloud altitudes and temperatures are reported.

\begin{tabular}{lcccccccrr}
\hline & $\mathrm{n} 1$ & $\mathrm{n} 2$ & $\mathrm{n} 3$ & $\mathrm{n} 4$ & $\mathrm{n} 5$ & $\mathrm{n} 6$ & $\mathrm{n} 7$ & $\mathrm{~T}\left({ }^{\circ} \mathrm{C}\right)$ & $\mathrm{alt}(\mathrm{m})$ \\
$D(\mu \mathrm{m})$ & $2.7-5.1$ & $5.1-8.3$ & $8.3-12.0$ & $12.0-16.3$ & $16.3-21.4$ & $21.4-25.4$ & $25.4-30.9$ & \\
\hline SCOUT-AMMA & & & & & & & & & \\
mean & 0.052 & 0.099 & 0.158 & 0.300 & 0.104 & 0.079 & 0.039 & -56 & 14080 \\
std & 0.183 & 0.355 & 0.568 & 1.072 & 0.370 & 0.280 & 0.141 & 26 & 5465 \\
\hline SCOUT Darwin & & & & & & & & & \\
mean & 0.013 & 0.015 & 0.009 & 0.012 & 0.003 & 0.001 & 0.001 & -78 & 16168 \\
std & 0.065 & 0.053 & 0.042 & 0.045 & 0.035 & 0.034 & 0.034 & 8 & 1223 \\
\hline TROCCINOX & & & & & & & & \\
mean & 0.060 & 0.062 & 0.043 & 0.051 & 0.015 & 0.005 & 0.004 & -72 & 15150 \\
std & 0.164 & 0.174 & 0.127 & 0.141 & 0.039 & 0.014 & 0.010 & 8 & 1230 \\
\hline
\end{tabular}

of a Mie scattering code available in the literature (Bohren and Huffman, 1983), by using the value of the refractive index accepted for ice particles (Toon et al., 1994).

The size distribution was considered stepwise constant over each of seven size bins, and the integral was approximated as in

$\beta=\sum_{i} \int_{\Delta_{i}} n_{i} \cdot \pi \cdot r^{2} \cdot Q(r) \cdot d r$

Results from earlier studies on backscatter calculations on volcanic particles have shown such calculation to be extremely sensitive to the histogram binning (Brock et al., 1993), at least for particles with diameters below $2 \mu \mathrm{m}$.

In order to rule out such dependency, an attempt to reconstruct the size distribution $n(r)$ in terms of analytic functions (bimodal lognormals) from the binned $n_{i}=n\left(r ; \Delta r_{i}\right)$ has been made on few selected cases. The Levenberg Marquardt algorithm was used in order to search for the coefficient values that minimize the chi-square. For size distributions with less than six points (number of fit coefficients) initial guesses for the coefficient values are required and have been adapted after visual inspection. Panels a to e in Fig. 2 shows five measured size distributions. Measurement error bars due to counting statistics are displayed only on panel a, for sake of clarity. Red lines represents bimodal lognormal fits to the measured size distributions.

We have then computed the backscatter coefficient for such bimodal lognormal fits and compared to what obtained from histograms. Results from such comparison are shown in panel f. Lognormal fits did not lead to large differences with respect to histograms, the discrepancy remaining on average within a factor of 2 . This is however smaller than the difference between the observed backscatter coefficient and that computed by optical scattering theory, which will be discussed later. This result is likely due to the fact that in our computation the scattering is dominated by large enough particles, for which the oscillation of the Mie backscattering coefficient is small, hence allowing us to rule out any appreciable dependency from the particular binning used on our optical computations.

Strictly speaking, Mie theory code applies to spherical scatterers, while more sophysticated matemathical tools would be necessary to take into account the asphericity of the scatterers (Macke , 1993; Reichardt et al., 2002; Scarchilli et al., 2005) However in this study we considered the uncertainties arising from the approximation of (2) with (3), and from the measurement uncertainties themselves, to be much higher than those arising from the spherical approximation in the computation of the scattering efficiencies. Generally speaking, aspherical scatterers depress the forward and backward scattering and enhance the side scattering with respect to surface equivalent spheres, so an overestimation of the backward scattering may be expected when using Mie codes. An educated guess of such overestimation can be provided by looking at studies comparing the phase function of aspherical vs spherical scatterers, which suggest an average overestimation of the Mie backscattering coefficient by a factor 2, which may possibly get as large as a factor 4 or more, depending on particle sizes and shapes (Mishchenko et al., 1996).

\subsection{Sensitivity tests}

The use of (3) to estimate (2) introduces systematic errors arising from the use of a stepwise function to approximate the true size distribution, and from limiting the interval of integration between the lower and upper detection limit of the FSSP, i.e. between $1.35 \mu \mathrm{m}$ and $15.5 \mu \mathrm{m}$ radius, instead of 

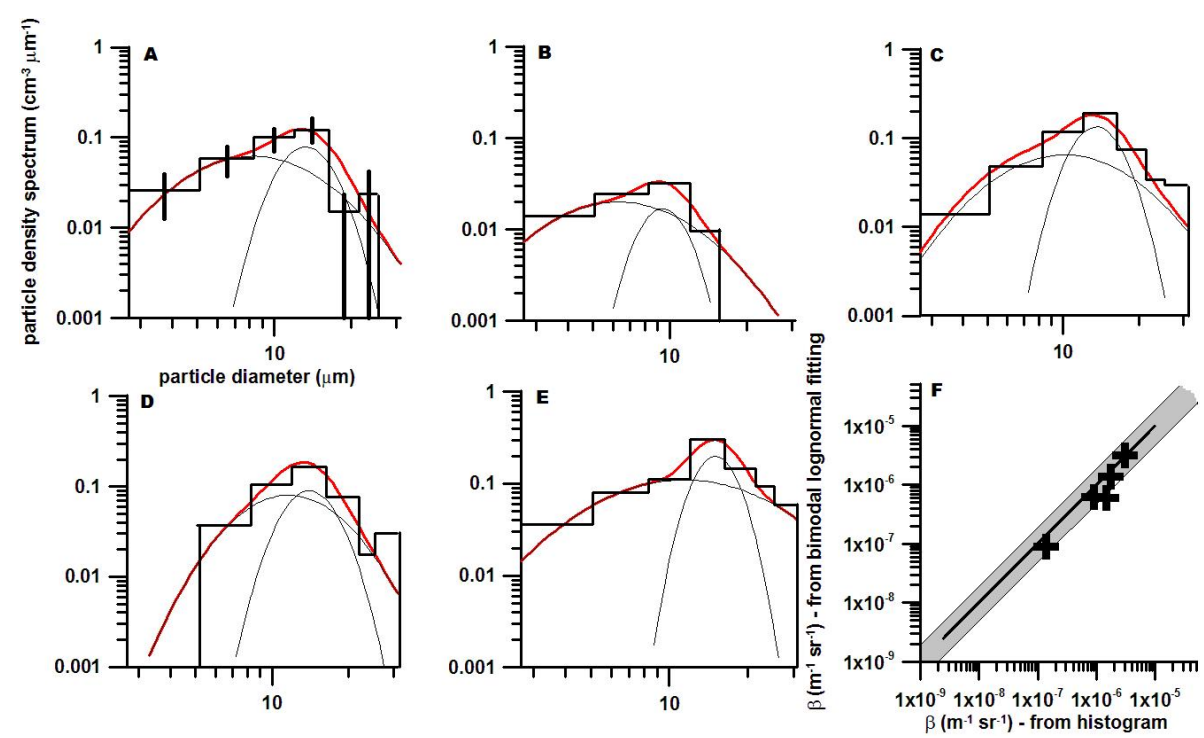

Fig. 2. Panels (A) through (E) show the histograms of the measured size distribution (black lines) with their error bars (shown only in panel (A) for sake of clarity) and their bimodal lognormal fitting functions (red lines). Thin black lines show the two monomodal contributing to the bimodal. In panel $(\mathbf{F})$ a scatterplot of backscattering coefficient computed from the histograms - horizontal axis - and from their respective bimodal lognormal fits - vertical axis - is displayed. A grey band marks the region where the mismatch stays below a factor 2 .

using the full range from 0 to $\infty$. In order to estimate the sensitivity of our calculations to the presence of undetected particles, we have computed the integral (3) for a set of case studies and compared with the result obtained by adding, to the measured size distribution, particles in an additional bin below the lower FSSP detection limit in one case, i.e. particles with radii extending from $0.35 \mu$ to $1.35 \mu$, and above the upper detection limit in a second case, i.e. particles with radii extending from $15.5 \mu$ to $16.5 \mu$.

To quantify the effects of undetected particles on optical parameters on one side, and on bulk size distribution parameters on the other, the particle number density $n_{i}$ in these additional bins was defined in order to allocate in such bins a volume, or surface, equivalent to those actually detected by the FSSP. This choice allows to easily extrapolate the effects of an arbitrary amount of undetected particles, just noting how, for particles uniformly distributed in these bins, their contribution to the optical parameters would scale linearly with their number, or volume, or surface.

This procedure allows to extrapolate the effects of an arbitrary number of undetected particles, by simultaneously scaling their consequences both on the optical and microphysical parameters of the particle distribution.

Results from these sensitivity tests are displayed in Fig. 3, where a scatterplot of the backscatter coefficient values from the incremented size distribution with respect to those computed from the size distribution actually measured, are displayed. On the left panel, the amount of additioned particles was chosen in order to double the total surface, in the right panel, in order to double the total volume; the colors indicate the addition of particles below (purple line) and above (blue line) the FSSP lower and upper detection limits, respectively.

The results of this analysis are the following:

1. Undetected particles whose radius is below the FSSP lower detection limit would have a large effect on the overall optical properties. In terms of volumes, an equal ratio of detected to non detected volumes would be mirrored in tenfold variations in the scattering coefficients; in terms of surfaces, an equal ratio of detected to non detected particles would double the backscattering coefficient.

2. Undetected particles whose radius is above the FSSP higher detection limit would have a smaller effect on the overall optical properties: an equal ratio of detected to non detected volumes would be mirrored in a twofold variation of the scattering coefficients, and similar effects would be produced by an equal ratio of detected vs non detected surfaces.

It should be noted that in our sensitivity study, we added particles in the $15.5-16.5 \mu \mathrm{m}$ radius range, close to the upper FSSP detection limit. Shifting their radius to larger values and keeping either their volume or their surface constant, would only decrease or leave practically unchanged their optical effectiveness; similarly, particles in the $0.35-1.35 \mu \mathrm{m}$ radius range would be more efficient in optical scattering, than a volume- or surface-equivalent number of particles within the FSSP detection limit, these properties descending from the general behaviour of scattering efficiencies versus particle dimension. Thus our choice in the sensitivity study represents an upper limit to the assessment of the effect of 

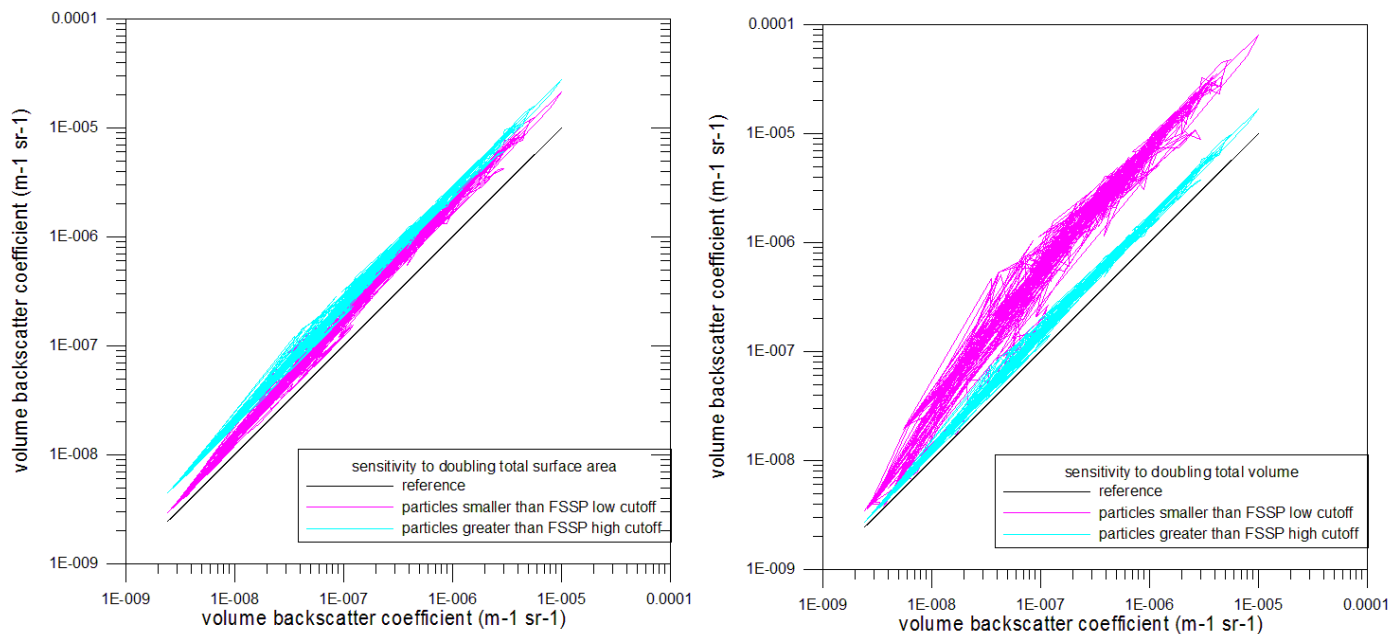

Fig. 3. Result of a sensitivity test, displaying a scatterplot of the Aerosol Backscatter Coefficient $\beta$ values computed from a set of experimentally determined size distributions, with particles artificially added, whose radius was below (purple line) and above (blue line) the FSSP detection limit, plotted agains $\beta$ from the unperturbed size distribution. The amount of additional particles was chosen to double the experimentally determined total surface area (left panel) or the total volume (right panel).

undetected particles, providing also a conservative estimate of the range of uncertainties one should expect on retrieved backscattering coefficients, for a given uncertainty on particle surfaces or volumes.

\section{Results and discussion}

Figure 4 presents typical results from our comparison of observed and retrieved backscattering coefficients. Time series are displayed, the black line representing the particle backscattering coefficient measured by the backscattersonde, and superimposed to that, a shaded area representing the same parameter retrieved from the measured size distribution, allowing an upper and a lower limit provided by the uncertainties on $n_{i}$ due to the counting statistics on each bin. In general the agreement is fair.

The left panel of Fig. 5 displays a scatterplot of observed vs computed backscattering coefficients, the colors coding different campaigns, together with frequency histograms for $\beta$, observed by the backscattersonde (vertical) and computed from FSSP particle observations (horizontal). Superimposed to the scatterplotted data points, a gray-coded Joint Probability Density Function (JPDF) for the two observables. For ease of representation, the JPDF colour scale is not uniform over the panel, but for the generic $(i, j)$ pixel, is normalized to the number of FSSP observations over the range $j$.

The backscattering coefficients spans over 5 orders of magnitude from subvisible to thick clouds. The correspondence between the two retrievals is good: they line up along the 1-1 correspondence with a scattering which is often below one order of magnitude and stays compact for $\beta$ ranging from $10^{-8}$ to $10^{-5} \mathrm{~m}^{-1} \mathrm{sr}^{-1}$. The correspondence is

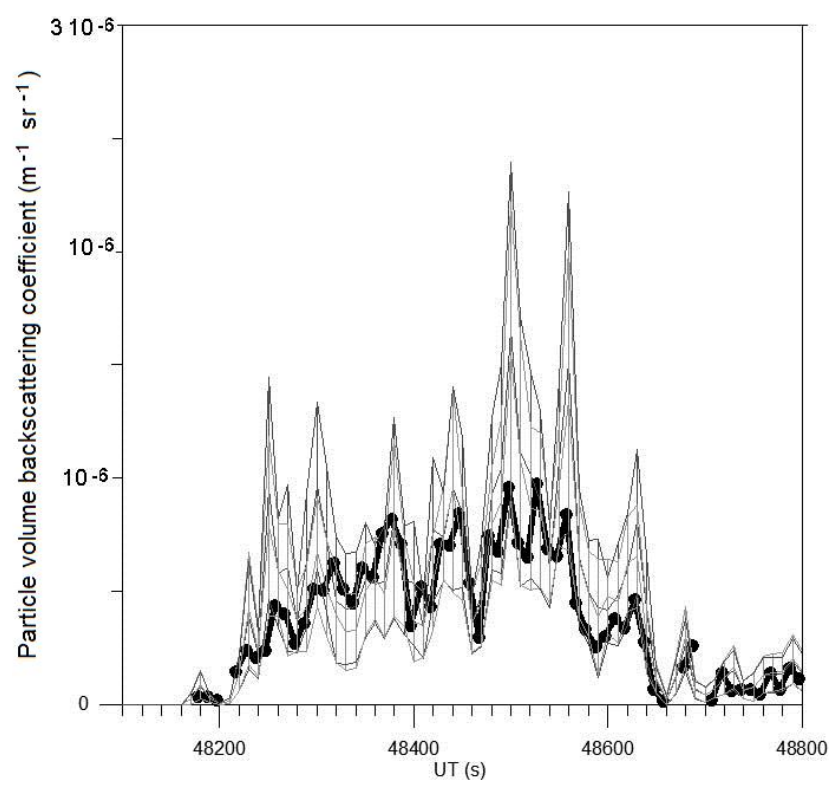

Fig. 4. Time series of aerosol backscattering coefficient $\beta$ are displayed, for a portion of the M55 Geophysica flight in cloudy air. The black line represents the parameter measured by the backscattersonde, the grey area superimposed to it represent the same parameter computed from the measured size distribution, allowing an upper and a lower limit provided by the uncertainties on the particle counting statistics.

more spread in the lower left corner of the graph, where small backscattering coefficients are probably more affected by measurement noise, and in the upper right corner where a bending can be discerned, probably due to a lack of linearity in the response of the backscattersonde to very thick 

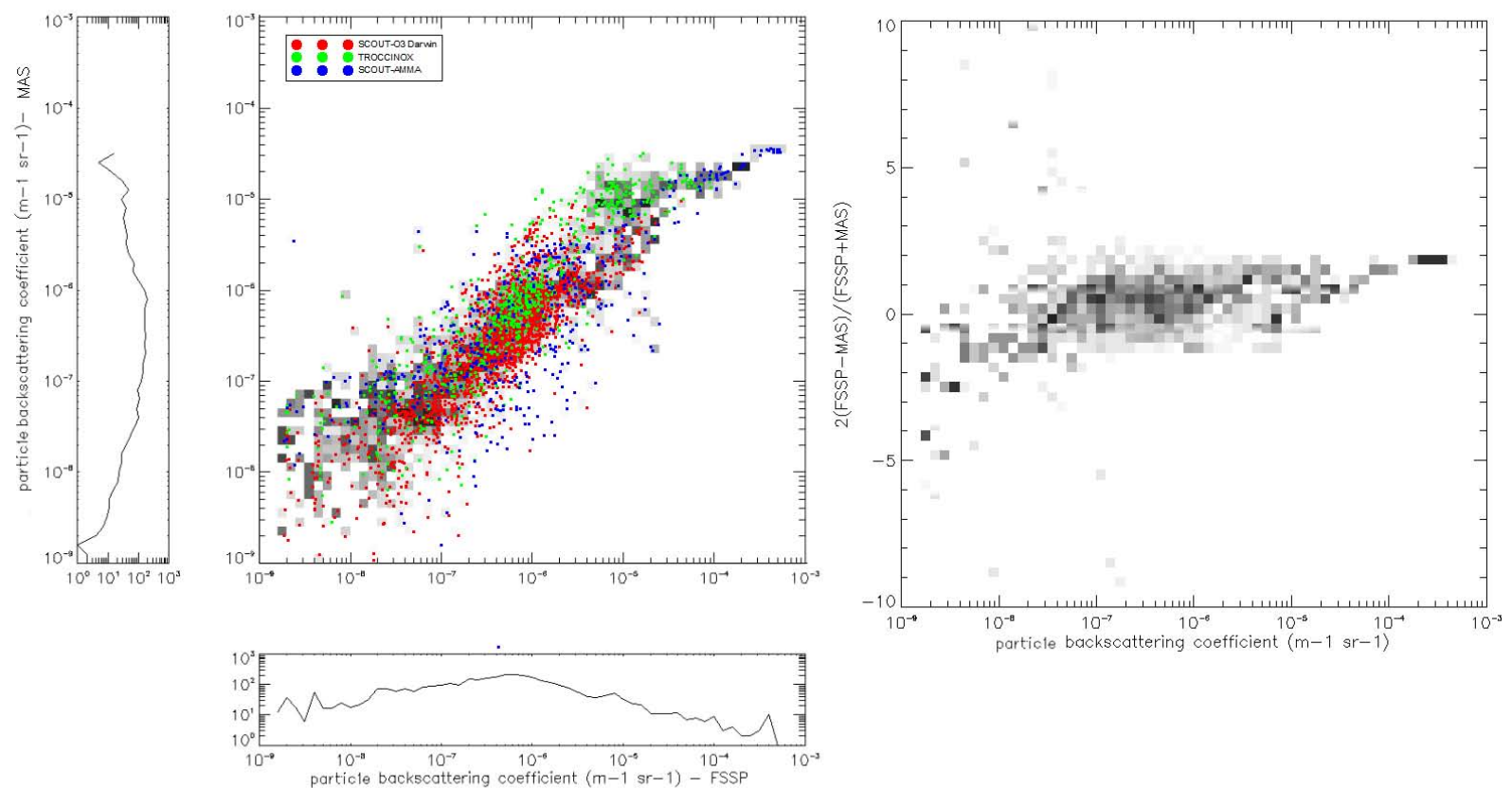

Fig. 5. Left panel: observation frequency histogram for $\beta$ measured by the backscattersonde (vertical, on the left) and computed from the particle size distribution (horizontal, below). The central part of the panel shows, in arbitrary units color coded in gray scale, the joint probability density distribution for the two quantities. Superimposed, a scatterplot of the two quantities where red, pale blue and deep blue dots represent data points from SCOUT-Darwin, TROCCINOX and SCOUT-AMMA campaigns respectively. Right panel: relative error between the $\beta$ optically measured, and computed from the particle size distribution.

clouds, this also confirmed from the observation frequency histogram, displaying a relative lack of backscattersonde observations for high $\beta$ values.

The dataset from different campaigns generally show a good agreement between observed and retrieved $\beta$. However, observations from SCOUT-AMMA look more dispersed than those from the other campaigns. This might be due to small different instrumental accuracies - due to changes in the detectors setups or laser alignment, power and stability, as instance - for the different deployments. Moreover, we observed in SCOUT-AMMA a more marked variability of cloud backscattering compared to what observed during SCOUT-Darwin and TROCCINOX. This might have introduced an additional source of uncertainty in the comparison. Whether the reason for this worse agreement between observed and retrieved $\beta$ in SCOUT-AMMA lies in instrumental artifacts or in actual physical differences between the datasets, could not be discerned.

The right panel of Fig. 5 shows the JPDF for the mismatch between retrieved and measured $\beta$ s versus its magnitude. The $\beta$ s agree within a factor 2 and are relatively unbiased except for very small $\beta$ values, when the measured one seems to be sistematically greater that the retrieved one, and for large $\beta$ values, when the opposite situation occurs, probably due to a lack of linearity in the response of the backscattersonde, as already noted.
We consider the correspondence in the central part of the variability range for $\beta$ extending for scarcely 4 orders of magnitude, fair enough, given the coarse approximations used in our computations, possible cloud inhomogeneity on spatial scales smaller than the distance between the two instruments, and uncertainties in the synchronization of the two instruments. This correspondence suggests that the portion of size distribution sampled by the FSSP is sufficient to account for the overall optical properties of tropical high cirrus clouds at $\lambda=532 \mathrm{~nm}$.

In discussing these dataset, we have to take into account the possibility of shattering effects, which is surely an issue in aircraft in situ particle detection. The issue for the present FSSP dataset has been extensively discussed in De Reus et al. (2009). There, the authors were able to rule out shattering effects for cloud IWC smaller than $10^{-4} \mathrm{~g} \mathrm{~m}^{-3}$, but - although there were good indications that the influence of shattering was small over the whole dataset - they were not able to definitely exclude it for the denser clouds. The reported IWC number, according to the $V-\beta$ relationship suggested in our work and discussed later on, translates into particle backscattering coefficients smaller than approximately $10^{-6} \mathrm{~m}^{-1} \mathrm{sr}^{-1}$, roughly in the middle of our magnitude range. Shattering effects are most prominent in clouds containing ice particles with sizes above several hundred microns. We selected cloud periods where the particles mostly were smaller or where the likelihood of having significant 

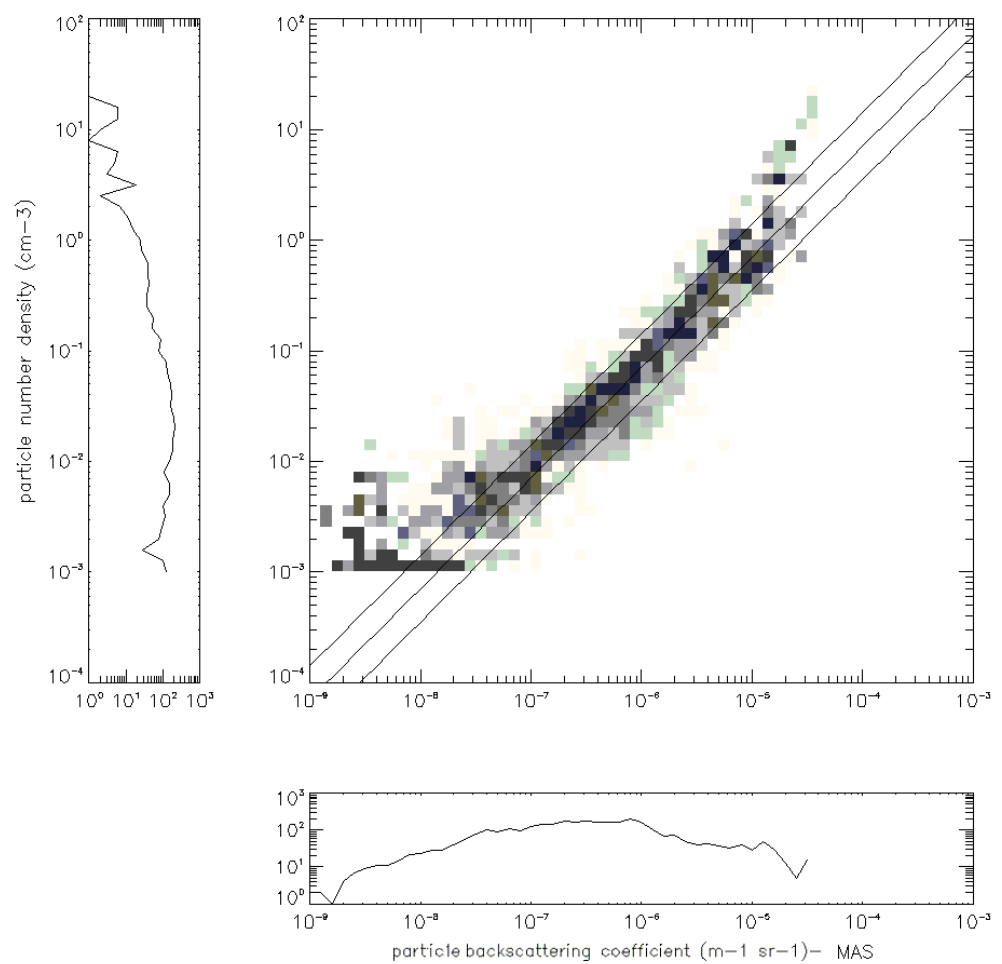

Fig. 6. Observation frequency histogram for $\beta$ measured by the backscattersonde (horizontal, below) and for the particle number density $N$ (vertical, on the left). The central panel shows, in arbitrary units color coded in gray scale, the joint probability density distribution for the two quantities. A linear fit with the parameters reported in Table 2, together with a region wheere the mismatch is below a factor 2, is also displayed.

numbers of (too) large particles was low. As instance, the cloud cases displayed in Figure 2 only contain particles with maximum sizes below $200 \mu \mathrm{m}$ and small number concentrations. Therefore, shattering is thought to have a minor or negligible effect (Lawson et al., 2008; Jensen et al., 2009). Moreover, these high tropical clouds seem to contain only simply structured particles (Lawson et al., 2010). This means plates, elongated spheriods, droxtals and not complex aggregates of crystals, rimed particles, complex hydrometeors. Such large particle aggregates cause considerable shattering effects. As a matter of fact, if there had been low concentrations of large particles present in the sampled air masses, then these would not have caused too much of a signal in the backscattersonde in comparison to the more abundant small particles. However these particles would have generated many shattered fragments which would have been detected as small particles by the FSSP. Then the FSSP derived backscatter ratios would strongly disagree (being consistently higher) with the MAS results. This is not the case. In fact, the size distribution detected by the FSSP well reproduces the observed backscattering, with no significant biases over its range of magnitude, i.e. from thinner to thicker clouds. This seems a good indication that an underestimation of large crystals and overestimation of small crystals has no leading effect, and shattering is not a major player in the sampled cloud volumes.

Figures 6, 7, 8 and 9 report in the horizontal axis the observations frequency histogram for the measured backscatter coefficient, in the vertical axis the observations frequency histograms for particle number density $N$, surface area density $S$, condensed volume density $V$ and effective radius $r_{\text {eff }}$ respectively. The central panels in each figure show the JPDF in gray scale, for each pair of variables under exam. As in Fig. 5, the JPDF colour scale is not uniform over the panel, but for the generic $(i, j)$ pixel it is normalized to the number of FSSP observations over that $j$.

The linearity between the observed $\beta$ and $N$ displayed in the JPDF panel in Fig. 6 is quite striking and indicates that $\beta$ basically scales with the particle number density $N$. This suggests that in the range of differences in the various shapes of the size distributions in our observations, these are practically uneffective in changing the scattering properties of cirrus clouds, at least for the wavelenght used in our study and for the dimensional range encountered in our observations. This finding is further confirmed by the correspondence of $\beta$ vs. $S$, as in Fig. 7, and vs. $V$ as in Fig. 8, which show the same linearity with $\beta$, although more scattered. 

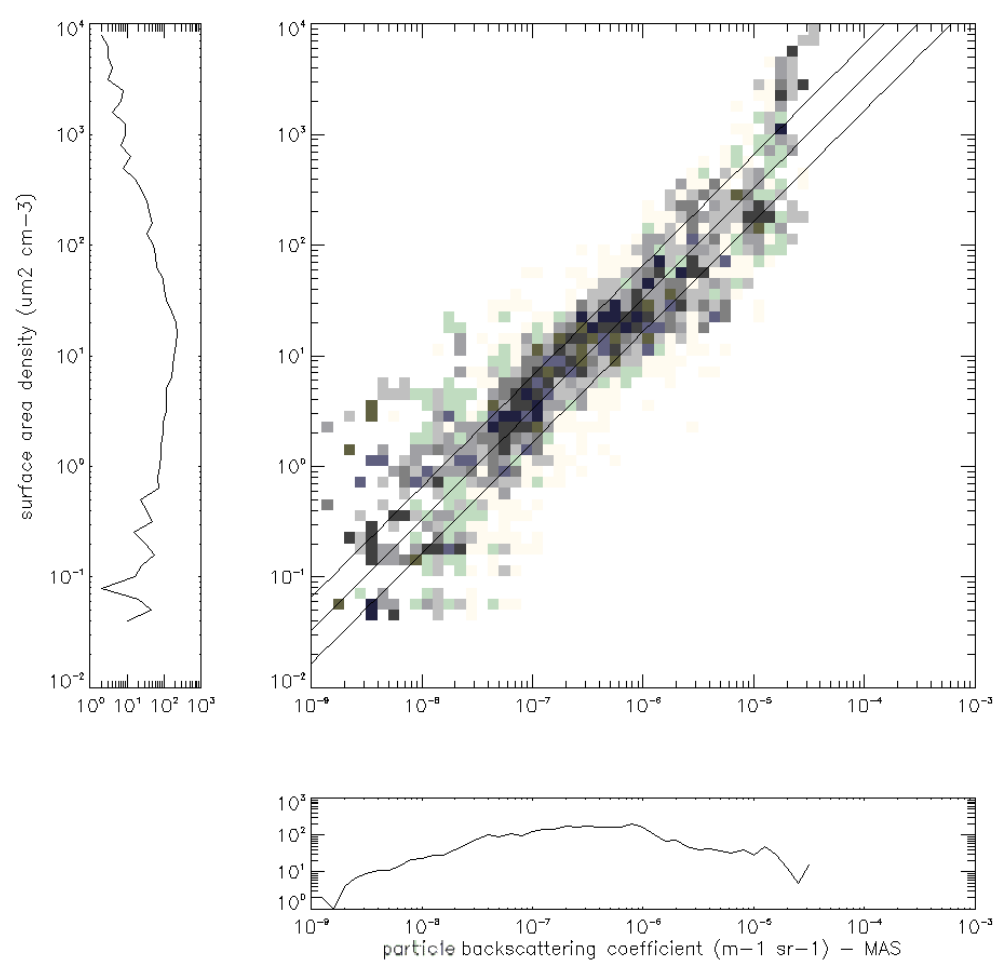

Fig. 7. Observation frequency histogram for $\beta$ measured by the backscattersonde (horizontal, below) and for the particle surface area density $\mathrm{S}$ (vertical, on the left). The central panel shows, in arbitrary units color coded in gray scale, the joint probability density distribution for the two quantities. A linear fit with the parameters reported in Table 2, together with a region wheere the mismatch is below a factor 2 , is also displayed.

In a recent work based on the same Geophysica cirrus clouds measurements during the SCOUT-Darwin campaign, De Reus et al. (2009) shows that the shapes of the size distributions display remarkably similar features, in the FSSP detection range, once normalized for the total number of particles. This again confirms $N$ as the main parameter governing the cirrus scattering properties at optical wavelenghts. In fact $\beta$ is relatively independent from $r_{\text {eff }}$ as can be discerned from Fig. 9, at least for large values of the backscattering coefficient. However this scaling may not be applicable throughout the whole $\beta$ range, since for small $\beta$ a correlation with $\mathrm{r}_{e f f}$ exists, as thinner cirrus tend also to have smaller effective radii.

Linear fits can be assessed between the particle bulk parameters and optical observations. A linear regression procedure has been applied in order to find the best fitting line passing through the origin. The fit was limited to the central part of the backscattering values, i.e. between $10^{-9}$ and $10^{-5} \mathrm{~m}^{-1} \mathrm{sr}^{-1}$, where the linear dependence seemed more robust. Such fits are reported in Figs. 6, 7 and 8, with a factor 2 band surrounding the fitted line, while the values of the angular coefficients, together with the $R$-squared of the fit, are reported in Table 2. By inspecting the figures, the uncertainty to be attributed to the bulk parameters inferred from such fits can be as large as a factor 2 for $N$, at least in
Table 2. Linear relations linking the backscatter coefficient to particle number, surface and volume density. Here $\beta$ is expressed in $\mathrm{m}^{-1} \mathrm{sr}^{-1}$, while $N, S$, and $V$ are expressed respectively in $\mathrm{cm}^{-3}$, $\mu \mathrm{m}^{-2} \mathrm{~cm}^{-3}, \mu \mathrm{m}^{-3} \mathrm{~cm}^{-3}$.

\begin{tabular}{lc}
\hline fit & R-squared \\
\hline$N=7.0 \times 10^{4} \times \beta$ & 0.73 \\
$S=3.2 \times 10^{7} \times \beta$ & 0.53 \\
$V=9.2 \times 10^{7} \times \beta$ & 0.49 \\
\hline
\end{tabular}

the central part of the backscattering variability range, while they increase both for the largest values - this probably due to a lack of linearity in the response of the backscattersonde - and for the smallest values of the backscattering, where the $\beta-N$ relationship became more scattered. The uncertainty increases for $S$ and, even more so, for $V$.

The question arise whether is reliable to use such relationships to infer the bulk properties of the size distribution from backscatter measurements which are normally accessible with remote sensing LIDARs. The question we have to answer can be stated as: to what extent the bulk parameters observed by the FSSP are representative of the real 

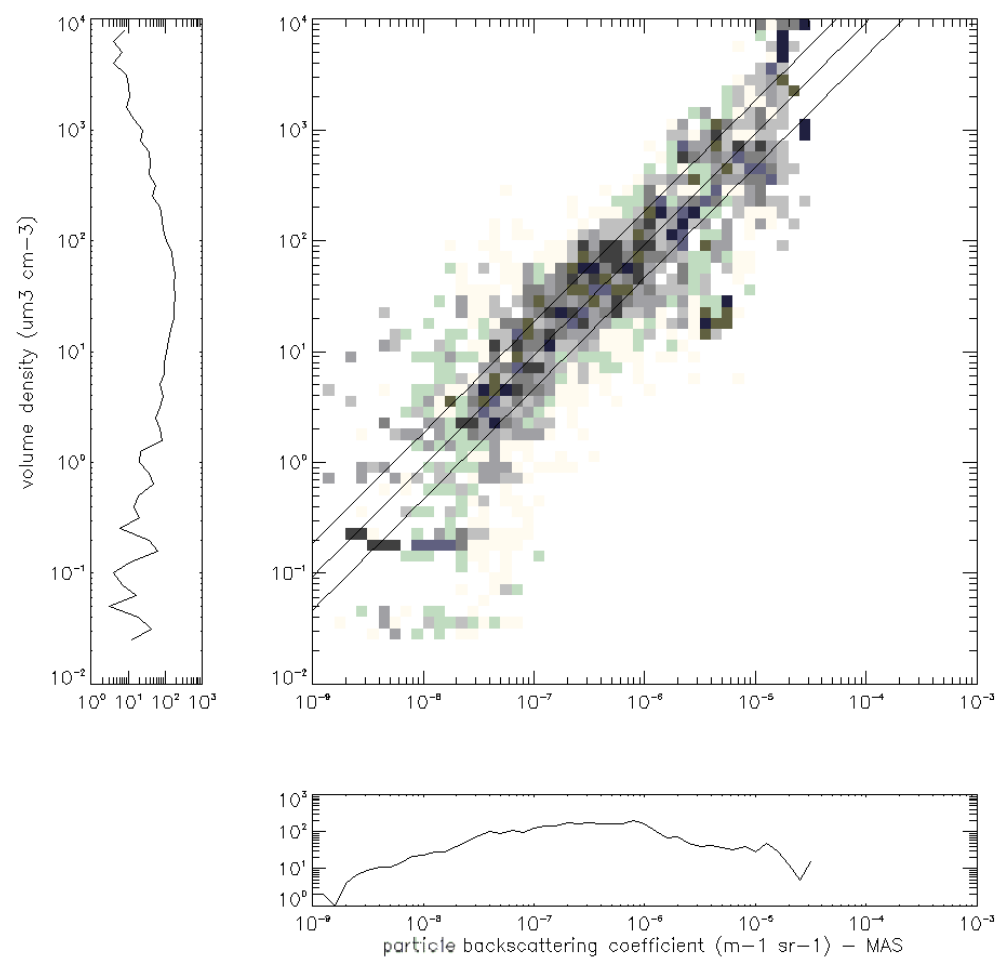

Fig. 8. Observation frequency histogram for $\beta$ measured by the backscattersonde (horizontal, below) and for the particle volume density $V$ (vertical, on the left). The central panel shows, in arbitrary units color coded in gray scale, the joint probability density distribution for the two quantities. A linear fit with the parameters reported in Table 2, together with a region wheere the mismatch is below a factor 2 , is also displayed.

parameters of the cloud, whose particle size distribution extends beyond the interval detected by the optical counter?

In the forementioned work, De Reus et al. (2009) complemented the FSSP size spectrum with the data from a second instrument on board the Geophysica, the Cloud Imaging Probe (CIP), a two dimensional optical array probe (Knollenberg , 1970) which detects and sizes particles with diameters between $25 \mu \mathrm{m}$ and $1.6 \mathrm{~mm}$. Volumes from these extended size spectra were then compared with the ice water content (IWC) measured by the two hygrometers on board. The good agreement between the two datasets allowed to put confidence in the reliability of the size distributions from the two optical instruments.

It is apparent from that study that the number of undetected particles outside the detection limit of the FSSP does not contribute significantly to the total number of particles. However, when it comes to particle surfaces and, to an even larger extent, volumes, undetected particles larger than the FSSP upper detection limit may play a significant role, so that the IWC retrieved from FSSP measurements can severely underestimate the real one. For the present study, we have performed similar comparisons between the FSSP particle volumes and those retrieved from the two hygrometers on board for selected cases, and found on few of them even a tenfold increase of particles volumes from particles undetected by the FSSP.

De Reus et al. (2009) found such effect more marked with increasing IWC, and $r_{\text {eff }}$, i.e. given the general trends of these two quantities with altitude, for thick, low cirrus clouds (Heymsfield and McFarquhar, 2002). Interestingly, the passage from the condition when the most of the total particle volume lies in the FSSP range, to when the most of it lies in the CIP range, occur around $10^{2} \mu \mathrm{m}^{3} \mathrm{~cm}^{-3}$.

Hence the $\beta-N$ relationship should be considered robust throughout the $\beta$ variability range, while care should be taken when trying to use Figs. 7 and 8 to retrieve cloud particle surfaces and volumes from backscattering measurements since the displayed correspondence between backscattering and total particle surfaces or volumes may lead to their underestimation. These discrepancies become more significant the optically denser the cloud. So for thick cirrus such relationships should only be considered as lower limits to $S$ and $V$.

\section{Conclusions}

A comparison of optical properties for tropical high altitude cirrus clouds, directly measured and inferred from particle size distribution observations, has been carried out. 

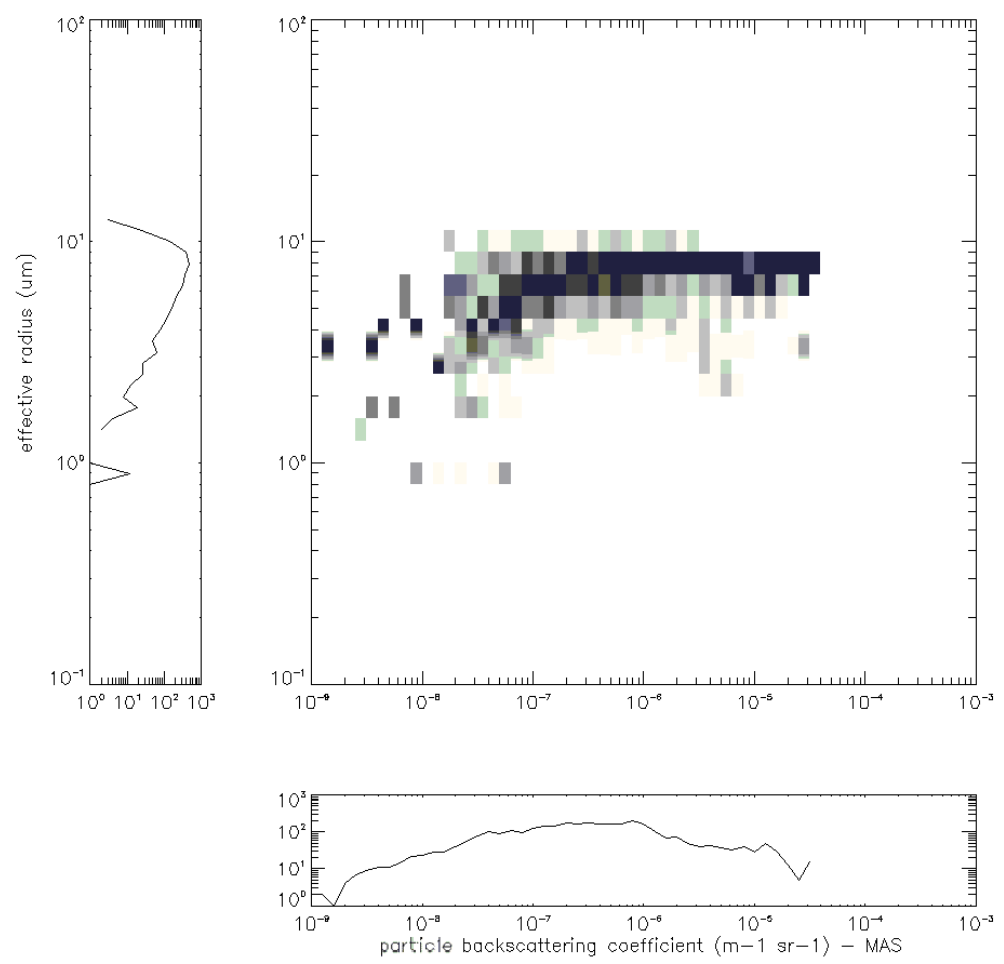

Fig. 9. Observation frequency histogram for $\beta$ measured by the backscattersonde (horizontal) and for the particle effective radius (vertical). The central panel shows, in arbitrary units color coded in gray scale, the joint probability density distribution for the two quantities.

Results suggest that the fraction of size spectrum available to FSSP particle counter observation, i.e. particles with diameters from 2.7 to $31 \mu \mathrm{m}$, is effective in reproducing cirrus optical properties in the visible part of the spectrum. This result keeps validity for backscattering cross sections spanning over 5 orders of magnitude. Optical particle counters observations are thus a valid tool to assess the cloud particle density and to provide size distributions for modelling cloud microphysical processes and radiative effects in the visible region of the spectrum.

A set of relations linking optical observations to microphysical bulk properties of the particle size distribution has been presented and discussed, with the aim to provide a tool to infer such microphysical properties from optical remote sensing measurements.

The results of our study suggest a robust linear relationship between particle concentration and backscattering coefficient. Similarly, relationships may be established also between backscattering and surface area and volume concentrations. However, some caveats must be put on the possibility to use backscattering measurements to infer particle surface or volume concentrations, due to the relatively scarce sensitivity of backscattering techniques for detecting particles above the FSSP upper detection limit. Hence such relationships should probably be regarded as providing only a lower limit for particle surface or, even more so, volume concentrations.
Acknowledgements. The TROCCINOX campaign was partially funded by the Commission of the European Community under the contract EVK2-CT-2001-00122 and by the DLR (Deutsches Zentrum fur Luft- und Raumfahrt) and other TROCCINOX partners. TROCCINOX was performed as a coordinated action of European and Brazilian research institutes and agencies together with the Brazilian project Tropical Convection and Cirrus Experiment Brazil (TroCCiBras),

The SCOUT-Darwin campaign was supported by the EC Integrated Project SCOUT-O3 (505390-GOCE-CT-2004).

The SCOUT-AMMA campaign was supported by the EEIGGeophysica Consortium, CNRS-INSU, EC Integrated Projects AMMA-EU (Contract Number 004089-2), SCOUT-O3 and CNES.

Based on a French initiative, AMMA was built by an international scientific group and is currently funded by a large number of agencies, especially from France, the United Kingdom, the United States, and Africa. It has been a beneficiary of a major financial contribution from the European Community Sixth Framework Programme (AMMA-EU). Detailed information on scientific coordination and funding is available on the AMMA International website at www.amma-international.org.

Edited by: N. Huret 


\section{References}

Böckmann, C., Wandinger, U., Ansmann, A., Bösenberg, J., Amiridis, V., Boselli, A., Delaval, A., De Tomasi, F., Frioud, M., Hågård, A., Horvat, M., Iarlori, M., Komguem, L., Kreipl, S., Larchevêque, G., Matthias, V., Papayannis, A., Pappalardo, G., Rocadembosch, F., Rodriguez, J. A., Schneider, J., Shcherbakov, V., and Wiegner M.: Aerosol lidar intercomparison in the framework of the EARLINET project, 2. Aerosol backscatter algorithms, Appl. Optics, 43(4), 977-989, doi:10.1364/AO.43.000977, 2004.

Bohren, C. F. and Huffman D. R.: Absorption and Scattering of Light by Small Particles, Wiley Interscience Publication, John Wiley and Sons, New York, 1983.

Brock, C. A., Jonsson, H. H., Wilson, J. C., Dye, J. E., Baumgardner, D., Borrmann, S., Pitts, M. C., Osborn, M. T., DeCoursey, R. J., and Woods, D. C.: Relationships between optical extinction, backscatter and aerosol surface and volume in the stratosphere following the eruption of Mt. Pinatubo, Geophys. Res. Lett., 20, 2555-2558, 1993.

Brunner, D., Siegmund, P., May, P. T., Chappel, L., Schiller, C., Müller, R., Peter, T., Fueglistaler, S., MacKenzie, A. R., Fix, A., Schlager, H., Allen, G., Fjaeraa, A. M., Streibel, M., and Harris, N. R. P.: The SCOUT-O3 Darwin Aircraft Campaign: rationale and meteorology, Atmos. Chem. Phys., 9, 93-117, doi:10.5194/acp-9-93-2009, 2009.

Buontempo, C., Cairo, F., Di Donfrancesco, G., Morbidini, R., Viterbini, M., and Adriani, A.:Optical measurements of atmospheric particles from airborne platforms, in situ and remote sensing instruments for balloons and aircrafts, Ann. Geophys.Italy, 49, 57-65, 2006.

Cairo, F., Adriani, A., Viterbini, M., Di Donfrancesco, G., Mitev, V., Matthey, R., Bastiano, M., Redaelli, G., Dragani, R., Ferretti, R., Rizi, V., Paolucci, T., Bernardini, L., Cacciani, M., Pace, G., and Fiocco, G.: Polar stratospheric clouds observed during the Airborne Polar Experiment Geophysica Aircraft in Antarctica (APE-GAIA) campaign, J. Geophys. Res., 109(690), D07204, doi:10.1029/2003JD003930, 2004.

Cairo, F., Pommereau, J. P., Law, K. S., Schlager, H., Garnier, A., Fierli, F., Ern, M., Streibel, M., Arabas, S., Borrmann, S., Berthelier, J. J., Blom, C., Christensen, T., D’Amato, F., Di Donfrancesco, G., Deshler, T., Diedhiou, A., Durry, G., Engelsen, O., Goutail, F., Harris, N. R. P., Kerstel, E. R. T., Khaykin, S., Konopka, P., Kylling, A., Larsen, N., Lebel, T., Liu, X., MacKenzie, A. R., Nielsen, J., Oulanowski, A., Parker, D. J., Pelon, J., Polcher, J., Pyle, J. A., Ravegnani, F., Rivière, E. D., Robinson, A. D., Röckmann, T., Schiller, C., Simões, F., Stefanutti, L., Stroh, F., Some, L., Siegmund, P., Sitnikov, N., Vernier, J. P., Volk, C. M., Voigt, C., von Hobe, M., Viciani, S., and Yushkov, V.: An introduction to the SCOUT-AMMA stratospheric aircraft, balloons and sondes campaign in West Africa, August 2006: rationale and roadmap, Atmos. Chem. Phys., 10, 2237-2256, doi:10.5194/acp-10-2237-2010, 2010.

Collis, R. T. H. and Russell, P. B.: Lidar Measurement of Particles and Gases by Elastic backscattering and Differential absorption, in: Laser Monitoring of the Atmosphere, edited by: Hinkley, E. D., Springer Verlag, Berlin, Germany, 1976.
Comstock, J. M. and Sassen K. : Retrieval of Cirrus Cloud Radiative and Backscattering Properties Using Combined Lidar and Infrared Radiometer (LIRAD) Measurements, J. Atmos. Ocean. Tech., 18, 1658-1673, 2001.

Corti, T., Luo, B. P., Fu, Q., Vömel, H., and Peter, T.: The impact of cirrus clouds on tropical troposphere-to-stratosphere transport, Atmos. Chem. Phys., 6, 2539-2547, doi:10.5194/acp-6-25392006, 2006.

de Reus, M., Borrmann, S., Bansemer, A., Heymsfield, A. J., Weigel, R., Schiller, C., Mitev, V., Frey, W., Kunkel, D., Kürten, A., Curtius, J., Sitnikov, N. M., Ulanovsky, A., and Ravegnani, F.: Evidence for ice particles in the tropical stratosphere from in-situ measurements, Atmos. Chem. Phys., 9, 6775-6792, doi:10.5194/acp-9-6775-2009, 2009.

Dye, J. E. D. and Baumgardner, D.: Evaluation of the forward scattering spectrometer probe I. Electronic and optical studies, J. Atmos. Ocean. Tech., 1, 329-344, 1984

Fernald, F. G.: Analysis of atmospheric lidar observations: some comments, Appl. Optics, 23, 7113-7131, 1984.

Hartmann, D. L., Holton, J. R., and Fu, Q.: The heat balance of the tropical tropopause, cirrus, and stratospheric dehydration, Geophys. Res. Lett., 28, 1969-1972, 2001.

Heymsfield, A. J.: Ice particles observed in a cirriform cloud at $-83{ }^{\circ} \mathrm{C}$ and implications for polar stratospheric clouds, J. Atmos. Sci., 43, 851-855, 1986.

Heymsfield, A. J. and McFarquhar, G. M.: Midlatitude and tropical Cirrus: Microphysical Properties, in: Cirrus, edited by: Lynch, D. K., Sassen, K., O’Starr, D., and Stephens, G., Oxford University Press, New York, 2002.

Holton, J. R. and Gettelman, A.: Horizontal transport and the dehydration of the stratosphere, Geophys. Res. Lett., 28, 2799-2802, 2001.

Immler, F., Krüger, K., Tegtmeier, S., Fujiwara, M., Fortuin, P., Verver, G., and Schrems, O.: Cirrus clouds, humidity, and dehydration in the tropical tropopause layer observed at Paramaribo, Suriname $\left(5.8^{\circ} \mathrm{N}, 55.2^{\circ} \mathrm{W}\right)$, J. Geophys. Res., 112, D03209, doi:10.1029/2006JD007440, 2007.

Jensen, E. J., Lawson, P., Baker, B., Pilson, B., Mo, Q., Heymsfield, A. J., Bansemer, A., Bui, T. P., McGill, M., Hlavka, D., Heymsfield, G., Platnick, S., Arnold, G. T., and Tanelli, S.: On the importance of small ice crystals in tropical anvil cirrus, Atmos. Chem. Phys., 9, 5519-5537, doi:10.5194/acp-9-5519-2009, 2009.

Klett, J. D.: Stable analytical inversion solution for processing lidar returns, Appl. Optics, 20, 211-220,1981.

Knollenberg, R. G.: The optical array: an alternative to scattering or extinction for airborne particle size determination, J. Appl. Meteorol., 9, 86-103, 1970.

Knollenberg, R. G., Kelly, K., and Wilson, J. C.: Measurements of high number densities of ice crystals in the tops of tropical cumulonimbus, J. Geophys. Res., 98, 8639-8664, 1993.

Lawson, R. P., Pilson, B., Baker, B., Mo, Q., Jensen, E., Pfister, L., and Bui, P.: Aircraft measurements of microphysical properties of subvisible cirrus in the tropical tropopause layer, Atmos. Chem. Phys., 8, 1609-1620, doi:10.5194/acp-8-1609-2008, 2008 . 
Lawson, R. P., Jensen, E., Mitchell, D. L., Baker, B., Mo, Q., and Pilson, B.: Microphysical and radiative properties of tropical clouds investigated in TC4 and NAMMA, J. Geophys. Res., 115, D00J08, doi:10.1029/2009JD013017, 2010.

Liou, K. N.: Influence of Cirrus Clouds on Weather and Climate Processes: A Global Perspective, Mon. Weather Rev., 114, 1167-1199, 1986.

Luo, B. P., Peter, T., Fueglistaler, S., Wernli, H., Wirth, M., Kiemle, C., Flentje, H., Yushkov, V. A., Khattatov, V., Rudakov, V., Thomas, A., Borrmann, S., Toci, G., Mazzinghi, P., Beuermann, J., Schiller, C., Cairo, F., Di Donfrancesco, G., Adriani, A., Volk, C. M., Strom, J., Noone, K., Mitev, V., MacKenzie, R. A., Carslaw, K. S., Trautmann, T., Santacesaria, V., and Stefanutti, L.: Dehydration potential of ultrathin clouds at the tropical tropopause, Geophys. Res. Lett., 30, 1557-1561, doi:10.1029/2002GL016737, 2003.

Macke, A.: Scattering of light by polyhedral ice crystals, Appl. Optics, 32, 2780-2788, 1993.

Matthias, V., Bösenberg, J., Freudenthaler, V., Amodeo, A., Balis, D., Chaikovsky, A., Chourdakis, G., Comeron, A., Delaval, A., de Tomasi, F., Eixmann, R., Hågård, A., Komguem, L., Kreipl, S., Matthey, R., Mattis, I., Rizi, V., Rodriguez, J. A., Simeonov, V., and Wang, X.: Aerosol lidar intercomparison in the framework of the EARLINET project, 1. Instruments, Appl. Optics, 43(12), 2578-2579, doi:10.1364/AO.43.002578, 2004.

McFarquhar, G. M., Heymsfield, A. J., Spinhirne, J., and Hart, B.: Thin and subvisual tropopause tropical cirrus: observations and radiative impacts, J. Atmos. Sci., 57, 1841-1853, 2000.

Mishchenko, M. I., Travis, L. D., and Mackowski, D. W.: T-matrix computations of light scattering by nonspherical particles: a review: J. Quant. Spectrosc. Ra., 55, 535-575, 1996.

Pace, G., Cacciani, M., di Sarra, A., Fiocco, G., and Fuá, D.: Lidar observations of equatorial cirrus clouds at Mahé, Seychelles, J. Geophys. Res., 108(D8), 4236, doi:10.1029/2002JD002710, 2003.

Pappalardo, G., Amodeo, A., Pandolfi, M., Wandinger, U., Ansmann, A., Bösenberg, J., Matthias, V., Amiridis, V., De Tomasi, F., Frioud, M., Iarlori, M., Komguem, L., Papayannis, A., Rocadenbosch, F., and Wang, X.: Aerosol lidar intercomparison in the framework of the EARLINET project, 3. Raman lidar algorithm for aerosol extinction, backscatter, and Lidar ratio, Appl. Optics, 43(28), 5370-5385, doi:10.1364/AO.43.005370, 2004.

Peter, Th., Luo, B. P., Wirth, M., Kiemle, C., Flentje, H., Yushkov, V. A., Khattatov, V., Rudakov, V., Thomas, A., Borrmann, S., Toci, G., Mazzinghi, P., Beuermann, J., Schiller, C., Cairo, F., Di Donfrancesco, G., Adriani, A., Volk, C. M., Strom, J., Noone, K., Mitev, V., MacKenzie, R. A., Carslaw, K. S., Trautmann, T., Santacesaria, V., and Stefanutti, L.: Ultrathin Tropical Tropopause Clouds (UTTCs): I. Cloud morphology and occurrence, Atmos. Chem. Phys., 3, 1083-1091, doi:10.5194/acp-3-1083-2003, 2003
Platt, C. M. R., Young, S. A., Manson, P. J., Patterson, G. R., Marsden, S. C., Austin, R. T., and Churnside, J. H.: The Optical Properties of Equatorial Cirrus from Observations in the ARM Pilot Radiation Observation Experiment, J. Atmos. Sci., 55, 19771996, 1998

Reichardt, J., Reichardt, S., Yang, P., and McGee, T. J.: Retrieval of polar stratospheric cloud microphysical properties from lidar measurements: Dependence on particle shape assumptions : SAGE III-Ozone Loss Validation Experiment and Third European Stratospheric Experiment on Ozone2000 (SOLVE/THESEO), J. Geophys. Res., 107, SOL 25.1SOL 25.12, 2002

Russell, P. B., Swissler, T. J., and McCormick, M., P.: Methodology for error analysis and simulation of lidar aerosol measurements, Appl. Optics, 18, 3783-3797, 1979.

Scarchilli, C., Adriani, A., Cairo, F., Di Donfrancesco, G., Buontempo, C., Snels, M., Moriconi, M. L., Deshler, T., Larsen, N., Luo, B., Mauersberger, K., Ovarlez, J., Rosen, J., and Schreiner, J.: Determination of polar stratospheric cloud particle refractive indices by use of in situ optical measurements and T-matrix calculations, Appl. Optics, 44, 3302-3311, 2005.

Schumann, U.: TROCCINOX - Tropical Convection, Cirrus and Nitrogen Oxides 795 Experiment, Overview, General Assembly 2005 of the European Geosciences Union, Vienna, Austria, 2429 April, 2005.

Thomas, A., Borrmann, S., Kiemle, C., Cairo, F., Volk, C. M., Beuermann, J., Lepuchov, B., Santacesaria, V., Matthey, R., Rudakov, V., Yushkov, V., Mackenzie, A. R., and Stefanutti, L.: In situ measurements of background aerosol and subvisible cirrus in the tropical tropopause region, J. Geophy. Res., 107, D2427, doi:2001JD001385, 2002.

Toon, O. B., Tolbert, M. A., Koehler, B. G., Middlebrook, A. M., and Jordan, J.: The infrared optical constants of $\mathrm{H}_{2} \mathrm{O}$ - ice, amorphous acid solutions, and nitric acid hydrates, J. Geophys. Res., 99, 25631-25654, 1994

Uthe, E. E. and Russell, P. B.: Lidar observations of tropical high altitude cirrus clouds, in: Radiation in the Atmosphere, edited by: Bolle, H. J., Science Press, Princeton, 1976.

Wang, J. R., Liu, G., Spinhirne, J. D., Racette, P., and Hart, W. D.: Observations and retrievals of cirrus cloud parameters using multichannel millimeter-wave radiometric measurements, J. Geophys. Res., 106(D14), 15251-15263, 2001.

Young, S. A.: Analysis of lidar backscatter profiles in optical thin clouds, Appl. Optics, 30, 7019-7024, 1995. 